\title{
Clinicopathological features and EGFR gene mutation status in elderly patients with resected non-small-cell lung cancer
}

Teppei Nishii ${ }^{1} 2^{*}$, Tomoyuki Yokose ${ }^{2}$, Yohei Miyagi ${ }^{3}$, Yataro Daigo ${ }^{4}$, Hiroyuki Ito ${ }^{1}$, Tetsuya Isaka ${ }^{1}$, Kentaro Imai ${ }^{1}$, Shuji Murakami ${ }^{1}$, Tetsuro Kondo ${ }^{1}$, Haruhiro Saito ${ }^{1}$, Fumihiro Oshita ${ }^{1}$, Kouzo Yamada', Shoichi Matsukuma ${ }^{3}$, Masahiro Tsuboi ${ }^{5}$, Haruhiko Nakayama ${ }^{1}$ and Munetaka Masuda ${ }^{6}$

\begin{abstract}
Background: The rapid aging of the population in Japan has been accompanied by an increased rate of surgery for lung cancer among elderly patients. It is thus an urgent priority to map out a treatment strategy for elderly patients with primary lung cancer. Although surgical resection remains standard treatment for early stage non-small-cell lung cancer (NSCLC), it is now essential to confirm the status of epidermal growth factor receptor (EGFR) gene mutations when planning treatment strategies. Furthermore, several studies have reported that EGFR mutations are an independent prognostic marker in NSCLC. However, the relations between age group and the molecular and pathological characteristics of NSCLC remain unclear. We studied the status of EGFR mutations in elderly patients with NSCLC and examined the relations of EGFR mutations to clinicopathological factors and outcomes according to age group.
\end{abstract}

Methods: A total of 388 consecutive patients with NSCLC who underwent complete tumor resection in our hospital from 2006 through 2008 were studied retrospectively. Formalin-fixed, paraffin-embedded tissue sections were used to isolate DNA from carcinoma lesions. Mutational analyses of EGFR gene exons 19, 20, and 21 and KRAS gene exons 12 and 13 were performed by loop-hybrid mobility shift assay, a highly sensitive polymerase chain reaction-based method.

Results: EGFR mutations were detected in 185 (47.7\%) and KRAS mutations were detected in 33 (8.5\%) of the 388 patients. EGFR mutations were found in a significantly higher proportion of patients younger than 80 years (younger group; 178/359, 49.6\%) than in patients 80 years or older (older group; $7 / 29,24.1 \%)(P=0.008)$. In contrast, KRAS mutations were more common in the older group $(6 / 29,20.7 \%)$ than in the younger group $(27 / 359,7.5 \%)$ $(P=0.014)$. The older group showed a trend toward a higher rate of 5 -year overall survival among elderly patients with EGFR mutations (100\%) than among those with wild-type EGFR (66.2\%), but the difference was not significant.

Conclusions: Our results suggest that the EGFR status of patients with NSCLC differs between patients 80 years or older and those younger than 80 years. EGFR mutation status might be a prognostic marker in elderly patients with completely resected NSCLC.

\footnotetext{
* Correspondence: t-nishii@kcch.jp

'Department of Thoracic Oncology, Kanagawa Cancer Center Hospital, 2-3-2

Nakao, Asahi-ku, Yokohama 2418515, Japan

2Department of Pathology, Kanagawa Cancer Center Hospital, 2-3-2 Nakao,

Asahi-ku, Yokohama 2418515, Japan

Full list of author information is available at the end of the article
} 


\section{Background}

Primary lung cancer remains the leading cause of the death from malignant tumors worldwide [1]. Non-smallcell lung cancer (NSCLC) accounts for approximately $80 \%$ of all cases of lung cancer [2]. Although surgical resection remains the standard treatment for early NSCLC, several molecular pathways have been shown to have prognostic significance in NSCLC. The epidermal growth factor receptor (EGFR) pathway is considered particularly important. EGFR is a membrane glycoprotein with an extracellular ligand-binding domain, a transmembrane lipophilic segment, and an intracellular domain that has tyrosine kinase activity. When a growth factor binds to EGFR, EGFR is self-phosphorylated by tyrosine kinase, and phosphorylated EGFR activates cellsignaling pathway involved in the regulation of cell cycle, apoptosis, angiogenesis, and cellular proliferation. Specific mutations of EGFR induce constant phosphorylation of EGFR, and increased levels of phosphorylated EGFR activate downstream signals that induce carcinogenesis [3,4]. EGFR mutations predict the effect of EGFR tyrosine kinase inhibitors (EGFR-TKI) [5,6]. It is now essential to confirm EGFR mutation status when planning treatment strategies for advanced or recurrent NSCLC.

The population of Japan is aging rapidly. In 2011 the average life-span in Japan was 83 years (males 79 years, females 86 years) [7]. Aging of the population is accompanied by a rapid increase in the incidence of primary lung cancer as well as the number of operations for lung cancer among elderly patients. Since 2009 persons 80 years or older have accounted for more than $10 \%$ of all patients in Japan. In 2011, patients 80 years old or older accounted for $11.5 \%$ of all patients [8-12]. Aging will become a global problem in the future, and knowledge acquired in Japan may contribute to solving related problems. Previous studies have suggested a relation between EGFR mutations and several clinicopathological factors, but whether EGFR status differs according to age group remains unclear. The present study assessed the status of EGFR mutations in elderly patients with NSCLC and examined the relations of EGFR mutations and clinicopathological factors to outcomes.

\section{Methods}

\section{Patients}

We retrospectively studied 388 consecutive patients with NSCLC who underwent complete tumor resection at Kanagawa Cancer Center Hospital (Yokohama, Japan) from 2006 through 2008. This study was approved by the ethics committee of the Kanagawa Cancer Center, and informed consent was obtained from all patients. The pathological diagnoses were independently made by 2 pathologists (T.N., T.Y.). Discrepancies in diagnoses were resolved by mutual agreement. The median follow-up time was 1981 days.

\section{Assessments}

Formalin-fixed, paraffin-embedded tissue sections of the resected tumors were used for DNA extraction. Mutational analyses of EGFR gene exons 19, 20, and 21 and KRAS gene exons 12 and 13 were performed by loop-hybrid mobility shift assay (LH-MSA), a highly sensitive polymerase chain reaction-based method, as described previously (Additional file 1: Table S1) [13].

\section{Statistical analysis}

Relations between EGFR status and categorical data were evaluated with the chi-square test. Continuous variables were compared by Student's t-test. Survival curves were plotted using the Kaplan-Meier method, and differences in survival rates were assessed using the log-rank test. $\mathrm{P}<0.05$ was considered to indicate statistical significance. Statistical manipulations were performed using the IBM SPSS Statistics 20 for Windows software system (IBM Corp, Armonk, NY, USA).

\section{Results}

\section{Relations between EGFR, KRAS status and}

\section{clinicopathological features}

The patients' characteristics are summarized in Table 1 . Of the 388 patients, 228 (58.8\%) were men, and 160 $(41.2 \%)$ were women. The mean age was 66.6 years (range, 35-90). EGFR mutations were detected in 185 patients $(185 / 388,47.7 \%)$ and KRAS mutations were detected in 33 (33/388, 8.5\%). EGFR mutations were found more frequently in women $(110 / 185,59.5 \%)$, adenocarcinoma $(183 / 185,98.9 \%)$, and non-smokers (106/185, $57.3 \%)(\mathrm{P}<0.001)$. Patients with EGFR mutation had fewer pre-existing cardiopulmonary comorbidities than patients with wild-type $(\mathrm{P}=0.028)$. The mean tumor diameter was smaller in patients with EGFR mutations $(2.68 \pm 0.92 \mathrm{~cm})$ than in those with wild-type EGFR $(3.35 \pm 1.71 \mathrm{~cm} ; \mathrm{P}<0.001)$. The rate of pathological T1 disease was significantly higher among patients with EGFR mutations $(114 / 185,61.6 \%)$ than among those with wild-type $E G F R(83 / 203,40.9 \%$; P $<0.001)$. In contrast, $K R A S$ mutations were not significantly related to gender, histopathological type, or smoking status. Although KRAS status did not correlate with pathological $\mathrm{T}$ factors, mean tumor diameter was larger in patients with KRAS mutations $(3.46 \pm 1.99 \mathrm{~cm})$ than in those with wild-type $K R A S$ $(2.99 \pm 1.36 \mathrm{~cm} ; \mathrm{P}=0.001)$.

\section{Relations between age group and clinicopathological features}

We divided the patients into two groups according to whether they were 80 years or older (older group) or 
Table 1 Correlations between EGFR mutations and clinicopathological features

\begin{tabular}{|c|c|c|c|c|c|c|c|}
\hline \multirow[t]{3}{*}{ Characteristics } & \multirow{3}{*}{$\begin{array}{l}\text { Total } \\
(n=388)\end{array}$} & \multicolumn{6}{|c|}{ No. of patients } \\
\hline & & \multicolumn{2}{|c|}{ EGFR status } & \multirow[t]{2}{*}{$p^{a}$} & \multicolumn{2}{|c|}{ KRAS status } & \multirow[t]{2}{*}{$p^{a}$} \\
\hline & & $\begin{array}{c}\text { Mutation } \\
(n=185,47.7 \%)\end{array}$ & $\begin{array}{c}\text { Wild-type } \\
(n=203,52.3 \%)\end{array}$ & & $\begin{array}{c}\text { Mutation } \\
(n=33,8.5 \%)\end{array}$ & $\begin{array}{c}\text { Wild-type } \\
(n=355,91.5 \%)\end{array}$ & \\
\hline Mean age, $\mathrm{yr} \pm \mathrm{SD}^{b}$ & $66.6 \pm 10.0$ & $65.1 \pm 10.3$ & $67.9 \pm 9.57$ & 0.462 & $68.6 \pm 9.11$ & $66.4 \pm 10.1$ & 0.553 \\
\hline Gender & & & & $<0.001$ & & & 0.552 \\
\hline Male & 228 & 75 & 153 & & 21 & 207 & \\
\hline Female & 160 & 110 & 50 & & 12 & 148 & \\
\hline Histological type & & & & $<0.001$ & & & 0.059 \\
\hline Adenocarcinoma & 302 & 183 & 119 & & 30 & 272 & \\
\hline Others & 86 & 2 & 84 & & 3 & 83 & \\
\hline \multicolumn{8}{|l|}{ Vascular invasion } \\
\hline Ly - & 314 & 155 & 159 & 0.172 & 25 & 289 & 0.429 \\
\hline Ly + & 74 & 30 & 44 & & 8 & 66 & \\
\hline V- & 261 & 151 & 110 & $<0.001$ & 23 & 238 & 0.756 \\
\hline$V+$ & 127 & 34 & 93 & & 10 & 117 & \\
\hline p-stage & & & & $<0.001$ & & & \\
\hline । & 293 & 155 & 138 & & 22 & 271 & 0.217 \\
\hline$\|/\|$ & 95 & 30 & 65 & & 11 & 84 & \\
\hline T-factor & & & & $<0.001$ & & & \\
\hline T1 & 197 & 114 & 83 & & 14 & 183 & 0.316 \\
\hline $\mathrm{T} 2 / 3$ & 191 & 71 & 120 & & 19 & 191 & \\
\hline Tumor diameter (cm) & $3.03 \pm 1.43$ & $2.68 \pm 0.92$ & $3.35 \pm 1.71$ & $<0.001$ & $3.46 \pm 1.99$ & $2.99 \pm 1.36$ & 0.001 \\
\hline $\mathrm{N}$-factor & & & & 0.348 & & & \\
\hline No & 322 & 157 & 165 & & 29 & 293 & 0.435 \\
\hline $\mathrm{N} 1 / 2$ & 66 & 28 & 38 & & 4 & 62 & \\
\hline Smoking status & & & & $<0.001$ & & & 0.107 \\
\hline Non-smoker & 157 & 106 & 51 & & 9 & 148 & \\
\hline Smoker & 231 & 79 & 152 & & 24 & 207 & \\
\hline Pre-existing cardiopulmonary comorbidity & 203 & 86 & 117 & 0.028 & 20 & 183 & 0.319 \\
\hline
\end{tabular}

$\mathrm{p}<0.05$ statistically significant

${ }^{b} \mathrm{SD}$, standard deviation.

EGFR, epidermal growth factor receptor; KRAS, v-Ki-ras2 Kirsten rat sarcoma viral oncogene homolog; ND, lymph node dissection.

younger than 80 years (younger group) and compared EGFR status and clinicopathological features between these age groups (Table 2). The younger group comprised 359 patients (92.5\%), and the older group comprised 29 (7.5\%). The proportion of patients with EGFR mutations was significantly higher in the younger group $(178 / 359$, $49.6 \%)$ than in the older group $(7 / 29,24.1 \% ; \mathrm{P}=0.008)$. In contrast, KRAS mutations were more common in the older group $(6 / 29,20.7 \%)$ than in the younger group $(27 / 359,7.5 \% ; \mathrm{P}=0.014)$. The proportion of smokers was significantly lower in the younger group (208/359, $57.9 \%)$ than in the older group $(23 / 29,79.3 \%$; $\mathrm{P}=0.024)$. Elderly patients had more pre-existing cardiopulmonary comorbidities than younger patients $(\mathrm{P}=0.024)$. Gender, histopathological type, vascular invasion, pathological stage, and tumor diameter did not differ significantly between the groups. We omitted lymph-node resection in the older group $(\mathrm{P}<0.001)$. Table 3 shows the region of EGFR mutation according to age group. Although the study group was small, there were no exon 20 mutations in the older group.

\section{Relations between EGFR status and outcomes}

Kaplan-Meier curve analysis showed that EGFR mutation status was significantly associated with survival (Figure 1). The 5-year overall survival rate was significantly higher in patients with EGFR mutations (90.2\%) than in those with wild-type EGFR (75.2\%) in the younger group $(\mathrm{P}<0.001$; Figure $1 \mathrm{~A})$. The 5 -year overall survival rate was slightly, but not significantly higher 
Table 2 Correlations between age group and clinicopathological features, including EGFR status

\begin{tabular}{|c|c|c|c|c|}
\hline \multirow[b]{2}{*}{ Characteristics } & \multicolumn{4}{|c|}{ No. of patients } \\
\hline & $\begin{array}{c}\text { Total } \\
(n=388)\end{array}$ & $\begin{array}{c}\geq 80 \text { years } \\
(n=29,7.5 \%)\end{array}$ & $\begin{array}{c}<80 \text { years } \\
(n=359,92.5 \%)\end{array}$ & $p^{a}$ \\
\hline Mean age, $y r \pm S D^{b}$ & $66.6 \pm 10.0$ & $82.6 \pm 2.41$ & $65.3 \pm 9.29$ & $<0.001$ \\
\hline Gender & & & & 0.246 \\
\hline Male & 228 & 20 & 208 & \\
\hline Female & 160 & 9 & 151 & \\
\hline Histology & & & & 0.034 \\
\hline Adenocarcinoma & 302 & 18 & 284 & \\
\hline others & 86 & 11 & 75 & \\
\hline \multicolumn{5}{|l|}{ Biomarker } \\
\hline EGFR wild type & 203 & 22 & 181 & 0.008 \\
\hline EGFR mutation & 185 & 7 & 178 & \\
\hline KRAS wild type & 355 & 23 & 332 & 0.014 \\
\hline KRAS mutation & 33 & 6 & 27 & \\
\hline \multicolumn{5}{|l|}{ Vascular invasion } \\
\hline Ly - & 314 & 26 & 288 & 0.214 \\
\hline Ly + & 74 & 3 & 71 & \\
\hline V- & 261 & 18 & 243 & 0.535 \\
\hline$V+$ & 127 & 11 & 116 & \\
\hline p-stage & & & & 0.080 \\
\hline । & 293 & 18 & 275 & \\
\hline$\|/\| I$ & 95 & 11 & 84 & \\
\hline T-factor & & & & 0.506 \\
\hline $\mathrm{T} 1$ & 197 & 13 & 184 & \\
\hline $\mathrm{T} 2 / 3$ & 191 & 16 & 175 & \\
\hline Tumor diameter (cm) & $3.03 \pm 1.43$ & $3.00 \pm 1.44$ & $3.40 \pm 1.24$ & 0.629 \\
\hline $\mathrm{N}$-factor & & & & 0.584 \\
\hline No & 322 & 23 & 299 & \\
\hline $\mathrm{N} 1 / 2$ & 66 & 6 & 60 & \\
\hline Operation & & & & 0.155 \\
\hline Limited resection (wedge/segmentectomy) & 80 & 3 & 77 & \\
\hline Standard surgery (lobectomy, pneumonectomy) & 308 & 26 & 282 & \\
\hline Lymph node resection & & & & $<0.001$ \\
\hline ND0/1/sampling & 109 & 25 & 156 & \\
\hline ND2 & 278 & 4 & 203 & \\
\hline Smoking & & & & 0.024 \\
\hline Non-smoker & 157 & 6 & 151 & \\
\hline Smoker & 231 & 23 & 208 & \\
\hline Pre-existing cardiopulmonary comorbidity & 203 & 21 & 182 & 0.024 \\
\hline
\end{tabular}

EGFR, epidermal growth factor receptor; KRAS, v-Ki-ras2 Kirsten rat sarcoma viral oncogene homolog; ND, lymph node dissection.

in patients with EGFR mutations (100\%) than in those with wild-type EGFR (66.2\%) in the older group $(\mathrm{P}=0.226$; Figure 1B).

\section{Discussion}

In the present study, we first evaluated EGFR mutations in resected NSCLC tissue by LH-MSA. LH-MSA is a 
Table 3 Region of EGFR mutation according to age group

\begin{tabular}{lrcr}
\hline & \multicolumn{3}{c}{ No. of patients } \\
\cline { 2 - 4 } EGFR mutations & Total & $\mathbf{8 0 0}$ years & $<\mathbf{8 0}$ years \\
\hline Exon 19 & 73 & 3 & 70 \\
Exon 20 & 13 & 0 & 13 \\
Exon 21 & 97 & 4 & 93 \\
Combined & 2 & 0 & 2 \\
\hline
\end{tabular}

highly sensitive polymerase chain reaction-based method. Sakuma et al. previously evaluated EGFR mutations by LH-MSA in our hospital. EGFR mutations were detected in $53.2 \%$ of NSCLCs and were significantly associated with adenocarcinoma, female sex, and no smoking history [14]. In the present study, we detected EGFR mutations in $47.7 \%$ of NSCLCs (Table 1). The presence of an EGFR mutation is closely linked to several clinicopathological factors, such as gender, smoking history, and pathological findings. Our results are consistent with those of recent studies reporting that the rate of EGFR mutations is higher among Asians (including Japanese), females, nonsmokers, and adenocarcinomas [14,15]. Although LH-MSA yet has not been generally performed, it is known to be a sensitive and low cost method in scanning the known gene mutation. Furthermore, we can treat many samples in a short time by LH-MSA. Nakajima et al. analyzed EGFR mutations using LH-MSA, and confirmed the results by direct sequencing. They concluded that LH-MSA has a high detection capability compared with direct sequencing [16]. Guideline from the College of American Pathologists, International Association for the Study of Lung Cancer, and Association for Molecular
Pathology indicate that LH-MSA compares favourably with the other method [17].

We then studied the relations between EGFR status and clinicopathological factors according to age group (Table 2). Past report suggested the impact of age on EGFR mutation, and concluded that age was associated with EGFR mutation in lung cancer [18]. In this study, if we analyze the EGFR status using the median age of 66 years old as a cutoff, there is no difference between younger and elderly group. Next, we divided the cohort in every ten years old, and we found that the rate of EGFR mutation suddenly decreased in a group 80 years or older. Because aging of the population is a global problem, the average life-span older than 80 years old in Japan was worthy of mention to the world. Due to the above reasons, we thought that the age of 80 years old is turning point in consideration of gene profile change, and divided the patients into two groups at 80 years of age. The older group ( $\geq 80$ years) of patients with NSCLC included significantly higher rates of non-adenocarcinoma, wild-type EGFR, KRAS mutations, and smokers. There was no difference between the older group and younger group in tumor size, T-factor, or pathological stage. Moreover, in Japan, females outlive males (males 79 years, females 86 years). Of the 29 elderly patients, 9 are females include 7 adenocarcinomas and 4 smokers. EGFR mutations were detected in 3 females. The 5-year overall survival rate was $100 \%$ regardless of EGFR mutation or wild type. When we examined the region of EGFR mutation according to age group (Table 3), no exon 20 mutations were found in the older group. Although our study group was small, our results suggest that EGFR mutation status might differ
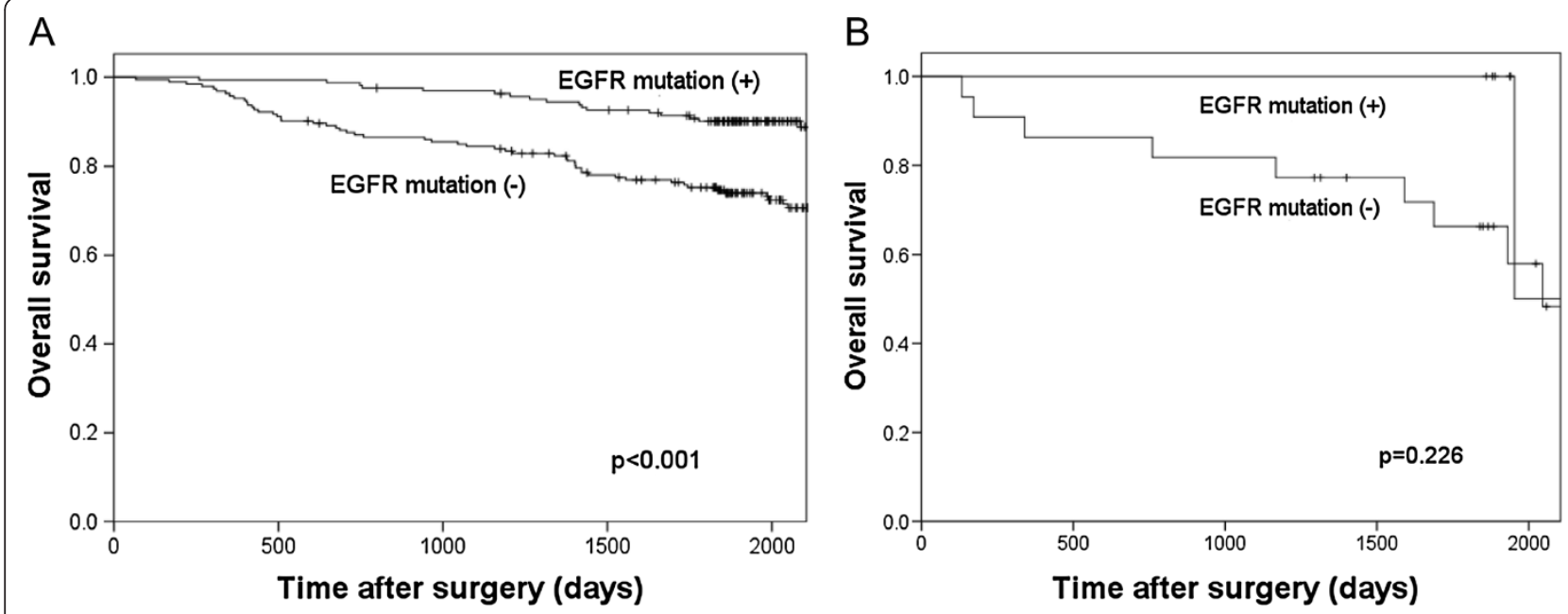

Figure 1 Relations between EGFR mutations and outcomes. Kaplan-Meier curve analysis showed that EGFR mutation status was significantly associated with survival. (A) The 5-year overall survival rate was higher in patients with EGFR mutations (90.2\%) than in those with wild-type EGFR (75.2\%) in the younger group ( $P<0.001)$. (B) In the older group, the 5-year disease free survival rate was $100 \%$ among patients with EGFR mutations; however, the difference between the two groups was not significant. 
between elderly and younger patients with NSCLCs. Given that smoking is one of the causes of the low rate of EGFR mutations in the older group, the rate of EGFR mutations may increase in the future owing to enlightenment movements such as the WHO Framework Convention on Tobacco Control [19]. Recently, smoking prevalence in Japan is decreasing generally. In particular, the drop of the smoking prevalence in young generation is remarkable. On the other hands, lung cancer mortality in Japan rises, probably it depends on the increase of the lung cancer in an elderly person who had been a smoker [20]. If the low rate of EGFR mutations is unrelated to smoking, it is very interesting that EGFR status might be affected by aging. Furthermore, it is reported that the response rate of gefitinib in elderly (aged 70 years or older) patients with advanced EGFR mutated NSCLC was $45.5 \%$. EGFR-TKI is more effective than conventional chemotherapy in elderly patients, if we could pay attention to drug discontinuation and dose reduction due to age-related organ dysfunction [21]. On the other hand, NSCLC with exon 20 mutation is resistant for EGFR-TKI. Although our result has no statistical significance due to a small population of elderly patients, the lack of exon 20 mutations might be a characteristic of elderly patients. Large clinical trials are needed to investigate the relation between age group and the response to EGFR-TKI.

Finally, we assessed the relations between the EGFR status and outcomes. EGFR mutations were associated with significantly better survival than wild-type EGFR in the younger group (Figure 1). In the older group, however, the 5 -year overall survival rate did not differ significantly according to EGFR mutations, and wild-type EGFR status and was $100 \%$ in patients with EGFR mutations. EGFRTKIs are obviously beneficial in patients with advanced or recurrent NSCLC, but several studies have suggested that EGFR mutations might be an independent positive prognostic factor [22]. Our results suggest that elderly patients with NSCLC who have EGFR mutations are especially likely to have good outcomes after complete lung resection.

\section{Conclusion}

Our results suggest that the EGFR status of patients with NSCLC differs according to age group ( $>80$ years vs. $\leq 80$ years). EGFR mutation status might be a prognostic marker in elderly patients with completely resected NSCLC.

\section{Additional file}

Additional file 1: Table S1. PCR Primers and LH-G Probes Used for Detection of Mutations in EGFR.

\section{Competing interests}

The authors declare that they have no competing interest.

\section{Authors' contributions}

Study design: TN, TY, YM and YD; sample collection: TN, HI, TI, KI, Shuji M, TK, HS, FO, KY, MT, and HN; experiments: TN, TY, YM, YD, and Shoichi M; data analysis: TN and TY; preparation of the manuscript: TN, TY, HN, and MM. All authors read and approved the final manuscript.

\section{Acknowledgements}

We thank Ms Sachie Osanai for technical assistance.

\section{Author details}

${ }^{1}$ Department of Thoracic Oncology, Kanagawa Cancer Center Hospital, 2-3-2 Nakao, Asahi-ku, Yokohama 2418515, Japan. ${ }^{2}$ Department of Pathology, Kanagawa Cancer Center Hospital, 2-3-2 Nakao, Asahi-ku, Yokohama 2418515, Japan. ${ }^{3}$ Molecular Pathology and Genetics Division, Kanagawa Cancer Center Research Institute, 2-3-2 Nakao, Asahi-ku, Yokohama 2418515 Japan. ${ }^{4}$ Department of Medical Oncology and Cancer Center, Shiga University of Medical Science Hospital, Seta Tsukinowa-cho, Otsu 5202192 Japan. ${ }^{5}$ Respiratory Disease Center, Yokohama City University Medical Center, 4-57 Urafune-cho, Minami-ku, Yokohama 2320024, Japan. ${ }^{6}$ Department of Surgery, Yokohama City University Graduate School of Medicine, 3-9 Fukuura, Kanazawa-ku, Yokohama 2360004, Japan.

Received: 6 April 2014 Accepted: 21 August 2014

Published: 25 August 2014

\section{References}

1. Jemal A, Siegel R, Xu J, Ward E: Cancer statistics, 2010. CA Cancer J Clin 2010, 60:277-300

2. Hoffman PC, Mauer AM, Vokes EE: Lung cancer. Lancet 2000, 355:479-485.

3. Hynes NE, Lane HA: ERBB receptors and cancer: the complexity of targeted inhibitors. Nat Rev Cancer 2005, 5:341-354.

4. Yarden $Y$, Sliwkowski MX: Untangling the ErbB signalling network. Nat Rev Mol Cell Biol 2001, 2:127-137.

5. Lynch TJ, Bell DW, Sordella R, Gurubhagavatula S, Okimoto RA, Brannigan BW, Harris PL, Haserlat SM, Supko JG, Haluska FG, Louis DN, Christiani DC, Settleman J, Haber DA: Activating mutations in the epidermal growth factor receptor underlying responsiveness of non-small-cell lung cancer to gefitinib. N Engl J Med 2004, 350:2129-2139.

6. Paez JG, Jänne PA, Lee JC, Tracy S, Greulich H, Gabriel S, Herman P, Kaye FJ, Lindeman N, Boggon TJ, Naoki K, Sasaki H, Fujii Y, Eck MJ, Sellers WR, Johnson BE, Meyerson M: EGFR mutations in lung cancer: correlation with clinical response to gefitinib therapy. Science 2004, 304:1497-1500.

7. World Health Statistics. 2013, http://www.who.int/gho/publications/ world_health_statistics/2013/en/.

8. Ueda $Y$, Fujii $Y$, Kuwano $\mathrm{H}$ : Thoracic and cardiovascular surgery in Japan during 2007. Annual report by the Japanese Association for Thoracic Surgery. Gen Thorac Cardiovasc Surg 2007, 2009(57):488-513.

9. Sakata R, Fujii $Y$, Kuwano H: Thoracic and cardiovascular surgery in Japan during 2008: annual report by The Japanese Association for Thoracic Surgery. Gen Thorac Cardiovasc Surg 2010, 58:356-383.

10. Sakata R, Fujii $\mathrm{Y}$, Kuwano $\mathrm{H}$ : Thoracic and cardiovascular surgery in Japan during 2009: annual report by the Japanese Association for Thoracic Surgery. Gen Thorac Cardiovasc Surg 2011, 59:636-667.

11. Kuwano H, Amano J, Yokomise $\mathrm{H}$ : Thoracic and cardiovascular surgery in Japan during 2010: annual report by The Japanese Association for Thoracic Surgery. Gen Thorac Cardiovasc Surg 2012, 60:680-708.

12. Amano J, Kuwano H, Yokomise H: Thoracic and cardiovascular surgery in Japan during 2011: Annual report by The Japanese Association for Thoracic Surgery. Gen Thorac Cardiovasc Surg 2011, 2013(61):578-607.

13. Matsukuma S, Yoshihara M, Kasai F, Kato A, Yoshida A, Akaike M, Kobayashi O, Nakayama H, Sakuma Y, Yoshida T, Kameda Y, Tsuchiya E, Miyagi Y: Rapid and simple detection of hot spot point mutations of epidermal growth factor receptor, BRAF, and NRAS in cancers using the loop-hybrid mobility shift assay. J Mol Diagn 2006, 8:504-512.

14. Sakuma Y, Matsukuma S, Yoshihara M, Nakamura Y, Noda K, Nakayama H, Kameda Y, Tsuchiya E, Miyagi Y: Distinctive evaluation of nonmucinous and mucinous subtypes of bronchioloalveolar carcinomas in EGFR and K-ras gene-mutation analyses for Japanese lung adenocarcinomas: confirmation of the correlations with histologic subtypes and gene mutations. Am J Clin Pathol 2007, 128:100-108. 
15. Mitsudomi $T$, Yatabe $Y$ : Mutations of the epidermal growth factor receptor gene and related genes as determinants of epidermal growth factor receptor tyrosine kinase inhibitors sensitivity in lung cancer. Cancer Sci 2007, 98:1817-1824.

16. Nakajima T, Yasufuku K, Suzuki M, Hiroshima K, Kubo R, Mohammed S, Miyagi Y, Matsukuma S, Sekine Y, Fujisawa T: Assessment of epidermal growth factor receptor mutation by endobronchial ultrasound-guided transbronchial needle aspiration. Chest 2007, 132:597-602.

17. Lindeman NI, Cagle PT, Beasley MB, Chitale DA, Dacic S, Giaccone G, Jenkins RB, Kwiatkowski DJ, Saldivar JS, Squire J, Thunnissen E, Ladanyi M: Molecular testing guideline for selection of lung cancer patients for EGFR and ALK tyrosine kinase inhibitors: guideline from the College of American Pathologists, International Association for the Study of Lung Cancer, and Association for Molecular Pathology. J Thorac Oncol 2013, 8:823-859.

18. Ueno T, Toyooka S, Suda K, Soh J, Yatabe Y, Miyoshi S, Matsuo K, Mitsudomi T: Impact of age on epidermal growth factor receptor mutation in lung cancer. Lung Cancer 2012, 78:207-211.

19. WHO Framework Convention on Tobacco Control. http:/www.who.int/ fctc/en/.

20. Funatogawa I, Funatogawa T, Yano E: Trends in smoking and lung cancer mortality in Japan, by birth cohort, 1949-2010. Bull World Health Organ 2013, 91:332-340.

21. Fujita S, Katakami N, Masago K, Yoshioka H, Tomii K, Kaneda T, Hirabayashi M, Kunimasa K, Morizane T, Mio T: Customized chemotherapy based on epidermal growth factor receptor mutation status for elderly patients with advanced non-small-cell lung cancer: a phase II trial. BMC Cancer 2012, 12:185. http://www.biomedcentral.com/1471-2407/12/185.

22. Izar B, Sequist L, Lee $M$, Muzikansky $A$, Heist $R$, lafrate J, Dias-Santagata $D$, Mathisen D, Lanuti M: The impact of EGFR mutation status on outcomes in patients with resected stage I non-small cell lung cancers. Ann Thorac Surg 2013, 96:962-968.

doi:10.1186/1471-2407-14-610

Cite this article as: Nishii et al: Clinicopathological features and EGFR gene mutation status in elderly patients with resected non-small-cell lung cancer. BMC Cancer 2014 14:610.

\section{Submit your next manuscript to BioMed Central and take full advantage of:}

- Convenient online submission

- Thorough peer review

- No space constraints or color figure charges

- Immediate publication on acceptance

- Inclusion in PubMed, CAS, Scopus and Google Scholar

- Research which is freely available for redistribution 